\title{
Sleep Tests in the Non-Contact Era of the COVID-19 Pandemic: Home Sleep Tests Versus In-Laboratory Polysomnography
}

\author{
Dae Wui Yoon ${ }^{1}$ (1) $\cdot$ Hyun-Woo Shin ${ }^{2,3,4,5}$ (1) \\ ${ }^{1}$ Department of Biomedical Laboratory Science, Jungwon University, Goesan; ${ }^{2}$ Obstructive Upper Airway Research (OUaR) Laboratory, \\ Department of Pharmacology, ${ }^{3}$ Ischemic/Hypoxic Disease Institute, and ${ }^{4}$ Cancer Research Institute, Seoul National University College of \\ Medicine, Seoul, ${ }^{5}$ Department of Otorhinolaryngology-Head and Neck Surgery, Seoul National University Hospital, Seoul, Korea
}

Coronavirus disease 2019 (COVID-19) is affecting millions of people around the world, both socially and economically, and has fundamentally changed people's lifestyles. Masks and disinfectants have become essential items and social distancing became inevitable in light of the finding that severe acute respiratory syndrome coronavirus 2 (SARS-CoV-2), the virus that causes COVID-19, could be detected in aerosols for several hours. Even in the absence of direct enforcement by the government, the tendency to avoid direct face-to-face contact seems to be widespread throughout our society. Many people are reluctant to come to the hospital because of concerns about contracting COVID-19 in the hospital. This leads to an important question: how should sleep tests be conducted in this non-contact era? Ultimately, the paradigm of sleep testing needs to be changed in response to this trend.

In-laboratory polysomnography (PSG) is the gold standard for diagnosing obstructive sleep apnea (OSA) because of its high diagnostic accuracy and low failure rate. These advantages of inlaboratory PSG may be due to the presence of a supervisor. Nonetheless, the disadvantages of in-laboratory PSG, including high costs, long waiting times, and hospital stays, could offset its merits. The first classification of portable monitors (PMs) divided them into four types according to the type and number of parameters and personnel attendance (type 1 to type 4) [1]. However, this classification of PMs did not reflect new technologies, and therefore an alternative categorization scheme including sleep, cardiovascular, oximetry, position, effort, and respiratory parameters (SCOPER) was developed in 2011 [2]. The American Academy of Sleep Medicine Task Force developed guidelines for the use of PMs without observation for the diagnosis of OSA in 2007 [3] and updated the information in 2017 [4]. The guide- lines recommend using PMs in patients with a high pretest probability of moderate to severe OSA without significant comorbid medical conditions. The use of a PM can also be considered if inlaboratory PSG is impossible due to immobility or serious illness.

Comparative studies have reported good diagnostic performance of PMs for suspected OSA patients, as demonstrated by strong agreement between the apnea-hypopnea index acquired from PMs and in-laboratory PSG. However, home sleep tests seem to have a higher failure rate than in-laboratory PSG $[5,6]$. Nonetheless, a recent randomized crossover study showed no significant differences in sensor quality and the number of non-interpretable tests between home sleep testing using type $2 \mathrm{PMs}$ and in-laboratory monitoring using the same type $2 \mathrm{PMs}$ [7].

As mentioned above, the clinical guidelines for the use of PMs limit the possible subjects to patients with a high pretest probability of moderate to severe OSA because of concerns that PM may have a higher false negative rate in the diagnosis of mild to mderate OSA. Indeed, the sensitivity and specificity of PMs for OSA vary depending on the severity of OSA and the type of monitor [8]. The recently developed type 3 PMs seem to have overcome the problem of low sensitivity, which is a disadvantage of existing PMs, even in mild OSA $[9,10]$. Whether OSA patients prefer a home sleep test or in-laboratory PSG depends on the hook-up location. When patients were hooked-up in the hospital and asked to return home for the sleep recording, the preference rate for home sleep monitoring was lower than that for in-laboratory testing [6,7]. When the hook-up was performed at patients' home, in contrast, the trend was reversed [11,12]. These results indicate that transportation is a critical factor determining patients' preference for a test location, and if transportation is inconvenient, patients will be willing to accept spending the night

Copyright () 2020 by Korean Society of Otorhinolaryngology-Head and Neck Surgery.

This is an open-access article distributed under the terms of the Creative Commons Attribution Non-Commercial License (https://creativecommons.org/licenses/by-nc/4.0) which permits unrestricted non-commercial use, distribution, and reproduction in any medium, provided the original work is properly cited. 
under observation in unfamiliar circumstances.

To address transportation-related concerns regarding home sleep tests, it is necessary to develop innovative PMs that can be easily worn and operated by patients at home. To minimize the failure rate, it is necessary to establish a self-monitoring system of sensor signals and to develop remotely controllable devices. Thanks to innovations in data transmission technology, this is no longer an impossible dream.

According to an evaluation of a hypothetical cohort of 1,000 Medicaid patients with suspected OSA [13], diagnostic testing using a type $3 \mathrm{PM}$ and the therapeutic strategy of home sleep monitoring with an auto-titrating continuous positive airway pressure (CPAP) device could save more than $\$ 400,000$ compared to in-laboratory PSG and in-laboratory PSG with a fixedtitration CPAP device. Considering the high cost of in-laboratory sleep tests, the deterioration of economic conditions due to the increase in unemployment resulting from COVID-19, and the increasing adoption of non-face-to-face-meetings in daily life, the transition to home sleep testing is an essential requirement in the current non-contact era.

\section{CONFLICT OF INTEREST}

No potential conflict of interest relevant to this article was reported.

\section{ORCID}

DaeWui Yoon https://orcid.org/0000-0001-8875-2255

Hyun-Woo Shin https://orcid.org/0000-0002-4038-9992

\section{AUTHOR CONTRIBUTIONS}

Conceptualization, Writing-original draft, review \& editing: all authors.

\section{REFERENCES}

1. Practice parameters for the use of portable recording in the assessment of obstructive sleep apnea. Standards of Practice Committee of the American Sleep Disorders Association. Sleep. 1994 Jun;17(4): 372-7.
2. Collop NA,Tracy SL, KapurV, Mehra R, Kuhlmann D, Fleishman SA, et al. Obstructive sleep apnea devices for out-of-center (OOC) testing: technology evaluation. J Clin Sleep Med. 2011 Oct;7(5):531-48.

3. Collop NA, Anderson WM, Boehlecke B, Claman D, Goldberg R, Gottlieb DJ, et al. Clinical guidelines for the use of unattended portable monitors in the diagnosis of obstructive sleep apnea in adult patients. Portable Monitoring Task Force of the American Academy of Sleep Medicine. J Clin Sleep Med. 2007 Dec;3(7):737-47.

4. KapurVK, Auckley DH, Chowdhuri S, Kuhlmann DC, Mehra R, Ramar K, et al. Clinical practice guideline for diagnostic testing for adult obstructive sleep apnea: An American Academy of Sleep Medicine Clinical Practice Guideline. J Clin Sleep Med. 2017 Mar;13(3):479504.

5. Flemons WW, Littner MR, Rowley JA, Gay P, Anderson WM, Hudgel DW, et al . Home diagnosis of sleep apnea: a systematic review of the literature: an evidence review cosponsored by the American Academy of Sleep Medicine, the American College of Chest Physicians, and the American Thoracic Society. Chest. 2003 Oct;124(4): 1543-79.

6. Portier F, Portmann A, Czernichow P, Vascaut L, Devin E, Benhamou D, et al. Evaluation of home versus laboratory polysomnography in the diagnosis of sleep apnea syndrome. Am J Respir Crit Care Med. 2000 Sep;162(3 Pt 1):814-8.

7. Yoon DW, Hong IH, Baik I, Shin HW. Evaluation of the feasibility and preference of Nox-A1 type 2 ambulatory device for unattended home sleep test: a randomized crossover study. Sleep Biol Rhythms. 2019 Jul;17(3):297-304.

8. Qaseem A, Dallas P, Owens DK, Starkey M, Holty JE, Shekelle P, et al. Diagnosis of obstructive sleep apnea in adults: a clinical practice guideline from the American College of Physicians. Ann Intern Med. 2014 Aug;161(3):210-20.

9. Xu L, Han F, Keenan BT, Kneeland-Szanto E, Yan H, Dong X, et al. Validation of the Nox-T3 portable monitor for diagnosis of obstructive sleep apnea in Chinese adults. J Clin Sleep Med. 2017 May; 13(5):675-83.

10. Cairns A, Wickwire E, Schaefer E, Nyanjom D. A pilot validation study for the NOX T3(TM) portable monitor for the detection of OSA. Sleep Breath. 2014 Sep;18(3):609-14.

11. Campbell AJ, Neill AM. Home set-up polysomnography in the assessment of suspected obstructive sleep apnea. J Sleep Res. 2011 Mar;20(1 Pt 2):207-13.

12. Bruyneel M, Sanida C, Art G, Libert W, Cuvelier L, Paesmans M, et al. Sleep efficiency during sleep studies: results of a prospective study comparing home-based and in-hospital polysomnography. J Sleep Res. 2011 Mar;20(1 Pt 2):201-6.

13. The New England Comparative Effectiveness Public Advisory Council. Diagnosis and treatment of obstructive sleep apnea in adults [Internet]. Boston, MA: Institute for Clinical \& Economic Review; 2013 [cited 2020 Oct 15]. Available from: https://icer-review.org/wp-content/uploads/2016/01/Final-Report_January20132.pdf. 